\title{
A comprehensive investigation into the effect of temperature variation on the mechanical properties of sustainable concrete
}

\author{
Abdulkader El Mir ${ }^{1, *}$, and Salem $\mathrm{Nehme}^{2}$ \\ ${ }^{1} \mathrm{PhD}$ student, Budapest University of Technology and Economics, Department of Construction \\ Materials and Technologies, Müegyetem rkp. 3, Budapest, Hungary \\ ${ }^{2}$ Assocaiate Professor, Budapest University of Technology and Economics, Department of \\ Construction Materials and Technologies, Müegyetem rkp. 3, Budapest, Hungary
}

\begin{abstract}
Minimizing the production energy and resources consumption are the key principle for engineering sustainability. In the case of concrete structures, this concept can be achieved by the use of materials in the most efficient way considering in the mix design the optimal mechanical and durability properties. The substitution of ordinary Portland cement for other supplementary cementitious materials is assessing the possibility of enhancing the sustainability and decreasing the environmental impact of concrete. Mass concrete is rich in cementitious materials which results in high temperature within the concrete, hence several hazards such as cracking or temperature differences between the interior and the surface of concrete could be prevented. An experimental study evaluated on several one cubic meter sized concrete elements in which during the primary phase of hydration, the temperature variation is recorded in several location offsets with respect to time. Thermal variations results are analyzed in accordance with the cement type, $\mathrm{CO}_{2}$ emission production of cement, compressive strength, water tightness, drying shrinkage and rapid chloride migration coefficient. The results indicate that slag cement CEM III/B 32.5, that incorporates highest amount of slag, ensured improved mechanical, thermal and durability properties in comparison with ordinary Portland cement CEM I 32.5.
\end{abstract}

\section{Introduction}

Over the few next decades, the production of concrete has been growing in the less developed countries (in Asia, Africa and parts of South America). Therefore, the problem of greenhouse gas emissions and the reduction of resources are likely to become a severe issue [1]. The concept of sustainability helps to improve the future of concrete production, providing encouraging potentials in reducing environmental impact. The main environmental problem in concrete production is the $\mathrm{CO}_{2}$ emission during cement creation. According to the U.S. Geological Survey, $5 \%$ of the global $\mathrm{CO}_{2}$ emissions are directly related to the production of

\footnotetext{
* Corresponding author: abdelkader.elmir@hotmail.com
} 
3.3 billion tons of cement per year [2]. Thus, substituting clinker is probably the most effective strategy to decrease the energy consumption in cement plants. For the concrete industry, when it comes to sustainability, simply it means providing more strength with lower emissions of $\mathrm{CO}_{2}$. In other words: more clinker made with less fuel, less implementation of cement in concrete, more strength and durability with less cement. Several earlier studies have already been carried out on this field [3-5]. This work was mainly based on clinker replacement by large amount of slag, fly ash or other supplementary cementitious materials, aiming for the achievement of a green concrete.

Mass concrete is widely applied in large projects. Hence, it becomes a necessity that concrete meets the requirements without cracking. Generally, massive concrete elements possess large section sizes. Therefore, after concrete placing, internal temperature rises drastically due to the heat of hydration.

Controlling the hydration heat from mass concrete during construction is a critical issue to obtain the targeted concrete quality. Blast furnace slag cement is mostly applied for construction projects where the strength undergoes a slow rate of development. By blending blast furnace slag with ordinary Portland cement, slag cement is produced with different classification depending on its mass replacement level of Portland cement. This paper aims to perform an objective comparison between three different types of local commercial cements in which the focus goes to the slag cement. The latter is analyzed in terms of the environmental impact, mechanical, thermal and durability properties of massive concrete.

\section{Experimental program}

\subsection{Materials}

In this study, three types of cement were used in order to produce three independent concrete mixtures. One ordinary Portland and two Blast furnace slag cement types were applied with different clinker and slag proportions (see Table 1).

Table 1. Cement properties.

\begin{tabular}{|l|l|l|l|l|l|}
\hline \multirow{2}{*}{ Cement type } & \multirow{2}{*}{$\begin{array}{l}\text { Blaine, } \\
\mathbf{c m}^{2} / \mathbf{g}\end{array}$} & \multicolumn{2}{|l|}{ Cement composition (\%) } & $\begin{array}{l}\text { Heat of hydration } \\
\text { (J/g), 41 hours }\end{array}$ \\
\cline { 3 - 6 } & & Clinker & $\begin{array}{l}\text { Blast } \\
\text { furnace } \\
\text { slag }\end{array}$ & $\begin{array}{l}\text { Lime- } \\
\text { stone }\end{array}$ & MSZ EN 196-9 \\
\hline $\begin{array}{l}\text { CEM I 32,5 N- } \\
\text { LH }\end{array}$ & 2419 & 97 & - & 3 & 241.0 \\
\hline $\begin{array}{l}\text { CEM III / A } \\
\text { 32,5 N-MSR }\end{array}$ & 3795 & 53 & 43 & 4 & 180.4 \\
\hline $\begin{array}{l}\text { CEM III / B } \\
\text { 32,5 N-LH/SR }\end{array}$ & 4505 & 32 & 65 & 3 & 169.8 \\
\hline
\end{tabular}

Materials were the same as the ordinary Portland cement which are produced in a local plant and modified depending on the percentage required for the slag into the cement composition. Danube quartz sand and gravel were used as aggregates for concrete preparation (maximum aggregate size was $16 \mathrm{~mm}$ ). Nominal grading fractions were used: sand $0 / 4 \mathrm{~mm}$, small gravel $4 / 8 \mathrm{~mm}$ and medium gravel $8 / 16 \mathrm{~mm}$. Water to cement ratio was set to be $\mathrm{w} / \mathrm{c}=$ 0.46 with constant cement amount of $330 \mathrm{~kg} / \mathrm{m} 2$. A relative low water to cement ratio was selected in order to reach enhanced durability properties. The superplasticizer "BASF 
Masterease 5007" was applied in order to obtain an F4 flow diameter classification with respect to European Standards [6].

Table 2. Mixtures proportion.

\begin{tabular}{|c|c|c|c|}
\hline Mixture ID & CEM I-32,5 & CEM III/A 32,5 & CEM III / B-32,5 \\
\hline cement type & $\begin{array}{l}\text { CEM I } 32,5 \\
\text { N-LH }\end{array}$ & $\begin{array}{l}\text { CEM III / A } \\
32,5 \text { N-MSR }\end{array}$ & $\begin{array}{l}\text { CEM III / B } \\
32,5 \text { N-LH/SR }\end{array}$ \\
\hline w/c ratio & 0.46 & 0.46 & 0.46 \\
\hline Cement $\left(\mathrm{kg} / \mathrm{m}^{3}\right)$ & 330 & 330 & 330 \\
\hline Sand $\left(\mathrm{kg} / \mathrm{m}^{3}\right)$ & 769 & 769 & 769 \\
\hline Small gravel $\left(\mathrm{kg} / \mathrm{m}^{3}\right)$ & 480 & 480 & 480 \\
\hline Medium gravel $\left(\mathrm{kg} / \mathrm{m}^{3}\right)$ & 673 & 673 & 673 \\
\hline Superplasticizer $\left(\mathrm{kg} / \mathrm{m}^{3}\right)$ & 4.65 & 5.34 & 5.55 \\
\hline
\end{tabular}

\subsection{In-situ and laboratory tests}

Three concrete cube blocks of $1 \mathrm{~m}^{3}$ were constructed with various types of cement. The concrete was delivered from a local ready-mix plants following by the common practice for placement and curing. A total of seven temperature sensors were implemented inside the concrete cube in several locations as indicated in Figs. 1a-b. Outdoor ambient temperature is recorded also along with the concrete ones. Total duration of temperature measurement from concrete placement took 7 days.

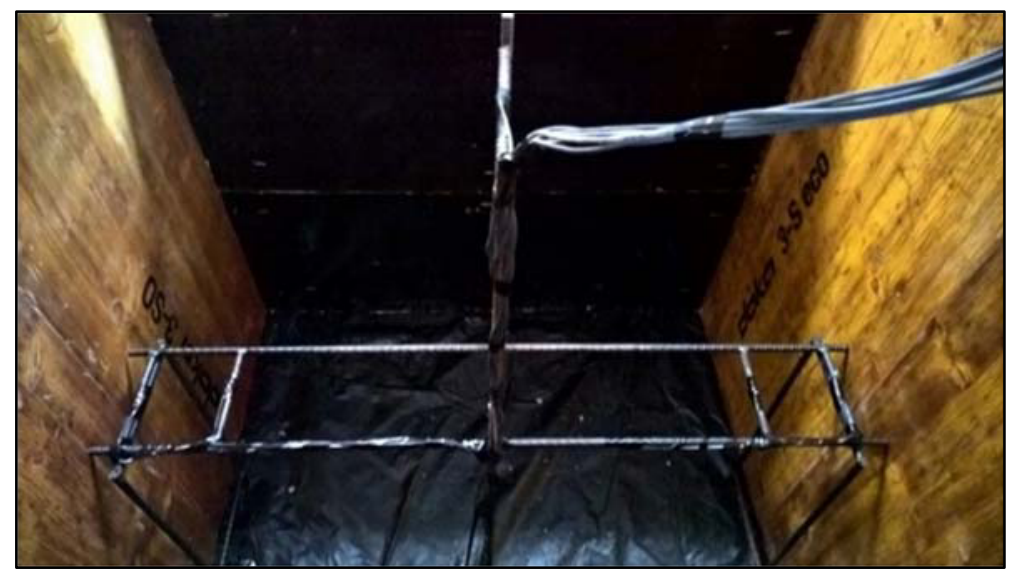

Fig. 1a. Instrumentation of the $1 \mathrm{~m}^{3}$ cube.

Several mechanical and durability tests were performed. Steel molds were placed on site and tested later in the laboratory. Cube specimens $(150 \times 150 \times 150 \mathrm{~mm})$ were tested for compressive strength using a universal closed-loop hydraulic testing machine performed based on European Standard [7] at a constant loading rate of $11.25 \mathrm{kN} / \mathrm{s}$. The testing age was of 2, 7, 28 and 56 days. Prismatic specimens $(75 \times 75 \times 250 \mathrm{~mm})$ were used to determine the drying shrinkage. After their removal from steel molds, the studs were glued on the four sides of the longitudinal surface of the concrete prism using a special adhesive. Demountable mechanical strain gauge (DEMEC), that can read up to $0.001 \mathrm{~mm}$, was the shrinkage measurement tool. Thereby the change in length of the specimens was measured between 1 and 77 days of curing time. 


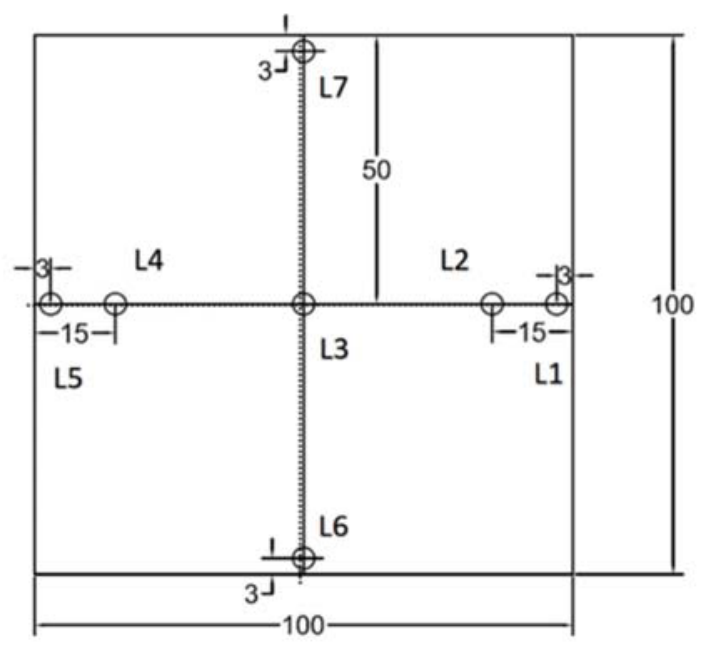

Fig. 1b. Schematic cross section of the sensors location in centimeters.

Referring to following European Standard [8], water tightness tests were performed on cubes specimens $(150 \times 150 \times 150 \mathrm{~mm})$ at the age of 72 days. Nevertheless, rapid chloride migration test was carried out on cylindrical specimens $(\varnothing 100 \times 50 \mathrm{~mm})$ according to the Nordtest Method NT Build 492 [9]. Tests were carried out at specimen age of 180 days.

\section{Results and discussion}

\subsection{Compressive strength}

The compressive strength values were determined using the cubes casted on-site. Fig. 2 . shows the compressive strength values versus the testing time at different ages. It can be seen that at the same conditions of curing and water to cement ratio, CEM III/B 32.5 exhibited the maximum compressive strength reaching a value of $68 \mathrm{MPa}$ at 56 days of age. Moreover, all cements having 32.5 grade showed almost similar compressive strength values at 56 days, ranging between 66 and $70 \mathrm{MPa}$. However, CEM I 32.5 provided a higher compressive strength at 7 and 28 days in comparison with CEM III/A 32.5 and CEM III/B 32.5. This behavior is explained by the effect of higher clinker content developing more the hydration reaction over the slag cement type (Higher strength rate development). The reduction in clinker content in case of CEM III/A 32.5 and CEM III/B 32.5 did not lead to a decrease in the compressive strength with respect to CEM I 32.5. Similar values were achieved at 28 days with clinker reduction up to $65 \%$ of slag. Hence, adequate strength values are obtained despite the low level of clinker. 


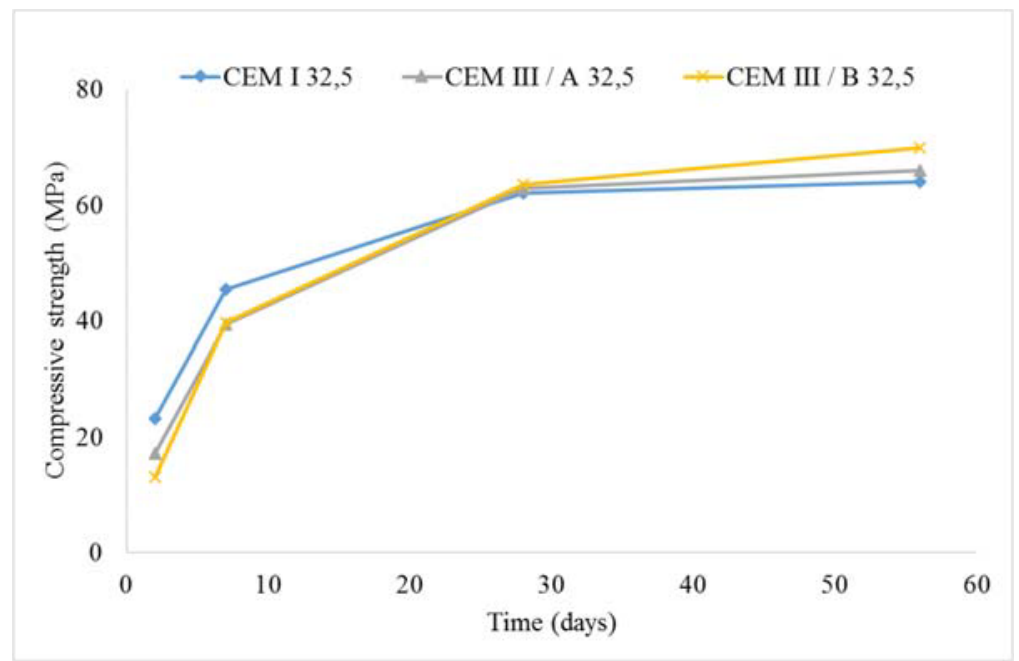

Fig. 2. Development of compressive strength with time in terms of applied cements.

\subsection{Drying shrinkage}

Shrinkage is a sensitive phenomenon resulting from the variation in the concrete volume and temperature, hence cracking problems could occur, in which are directly connected to corrosion and deterioration of the reinforcements [10]. Drying shrinkage arises when capillary water evaporates from the hardened concrete due to temperature variations with the ambient one. Fig. 3. shows the development of shrinkage of all concrete mixtures with different cement types over time. Test results shows that the drying shrinkage values of all mixtures, which is recorded up to 66 days, fell below 1000 microstrains at 56 days of age, which is considered adequate according to standards of Australia [11].

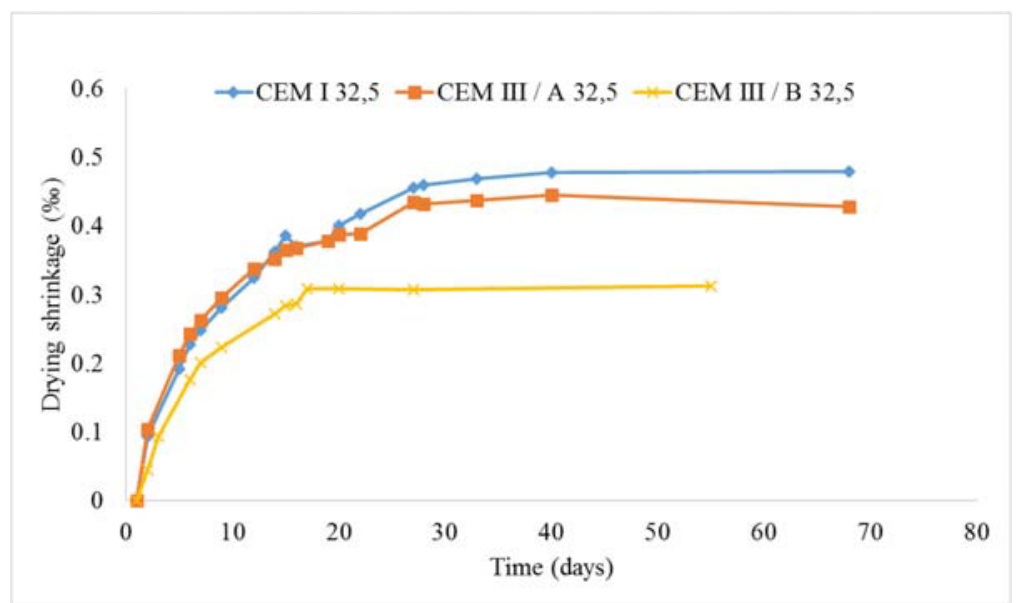

Fig. 3. Variation of drying shrinkage with time of the three applied cements.

At earlier ages, high shrinkage rates up to 16 days can be noticed for all mixtures. Afterwards, these values increase gradually till 30 days, and then slowly reduce after 30 days. The shrinkage of CEM I 32.5 reached the maximum value among all studied cements of 480 microstrains. When the slag was integrated into the concrete, drying shrinkage value 
decreased with the increase of slag content by $35 \%$ at $65 \%$ replacement level by slag referring to CEM I 32.5. Hence less drying shrinkage is obtained when the clinker is replaced by slag material.

\subsection{Effect of temperature on cement type}

The heat generated from cement hydration along with the variation of ambient temperature could cause cracks in the concrete [12-13]. It was also considered that the cement type directly affects the hydration heat [14].

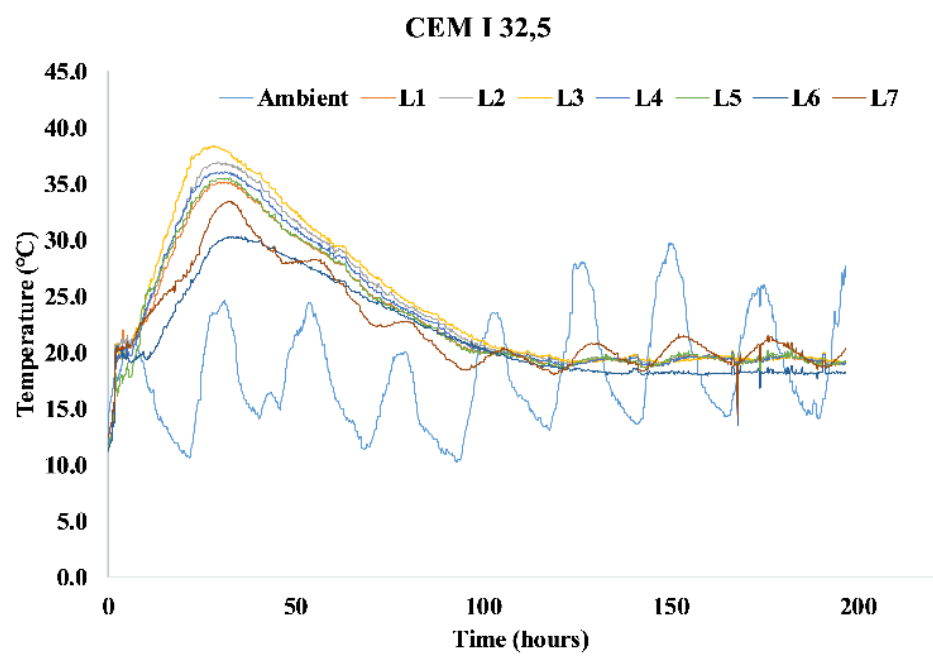

Fig. 4a. Temperature-time history for CEM I 32.5 at various locations in the cube.

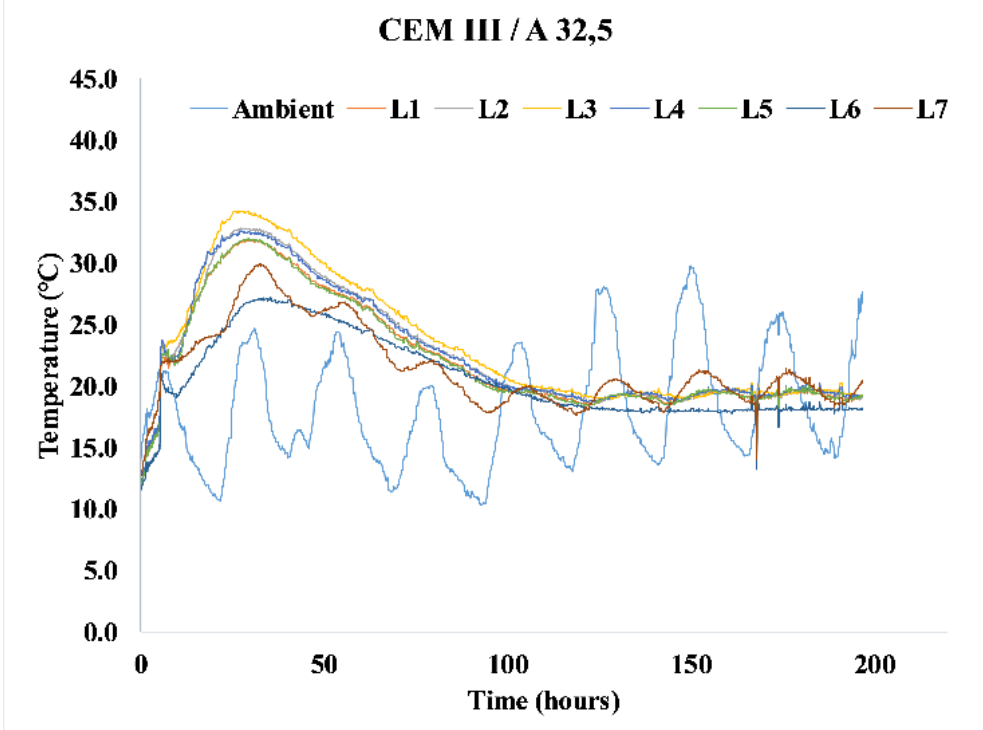

Fig. 4b. Temperature-time history for CEM III/A 32.5 at various locations in cubic cube. 
In order to demonstrate the influence of the size on the hydration heat, temperature sensors mentioned earlier in section 2.2 were located at different position in the cube element (Fig. 1a-b.). The variation of temperature with time at multiple locations were recorded as illustrated in Fig. 4a-c.

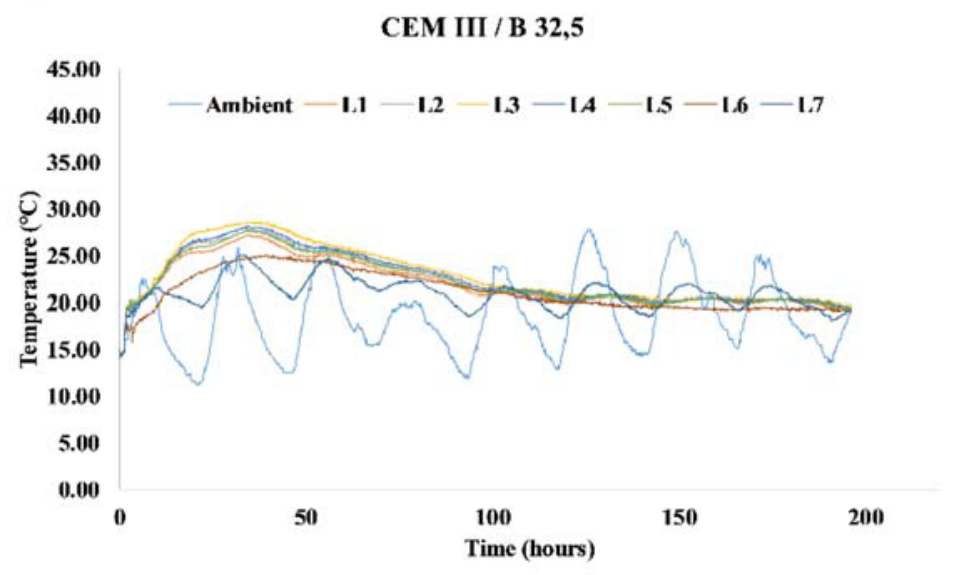

Fig. 4c. Temperature-time history for CEM III/B 32.5 at various locations the cube.

Highest temperature values were noted at the center of the $1 \mathrm{~m}^{3}$ element. Portland cement with high amount of clinker showed the maximum peak of temperature reaching $38^{\circ} \mathrm{Cin}$ case of CEM I 32.5. With the partial replacement of the Portland cement by slag, this value drops with the increase of slag content, reaching $27{ }^{\circ} \mathrm{C}$ in case of CEM III/B 32.5 (highest slag content). Regarding the locations of the sensors, temperature values recorded near to the surface, away from the center, showed how differences in temperature occur in mass concrete. However, in case of CEM III/ B 32.5 containing the highest amount of slag, temperature differences between inner and outer locations were not significant. Hence crack hazards and less tensile stresses are expected to appear inside the concrete element.

\subsection{Water tightness and rapid chloride migration coefficient}

Water penetration depth under pressure leads to some observations regarding the permeability of tested concrete. Fig. 5. shows that CEM III/ B 32.5 mixture has a low permeability, with a maximum penetration depth of $9 \mathrm{~mm}$. However, in case of CEM I 32.5 and CEM III/A 32.5, at same level of water cement ratio w/c = 0.46, their relevant concrete mixtures have higher penetration depth reaching $18 \mathrm{~mm}$. According to Neville, impermeable concrete falls into the $50 \mathrm{~mm}$ or less of water penetration depth. For values less than $30 \mathrm{~mm}$, concrete is classified under impermeable concrete for aggressive environmental exposure conditions [15]. On the other hand, the rapid chloride migration coefficient was recorded for all tested concretes. It can be clearly observed that the difference between slag and ordinary Portland cement in resisting the chloride migration. The latter showed a better response, along with the increase of the slag content in the cement composition. The CEM III/B 32.5 shows relatively better performance in resisting the chloride (Fig. 5.). 


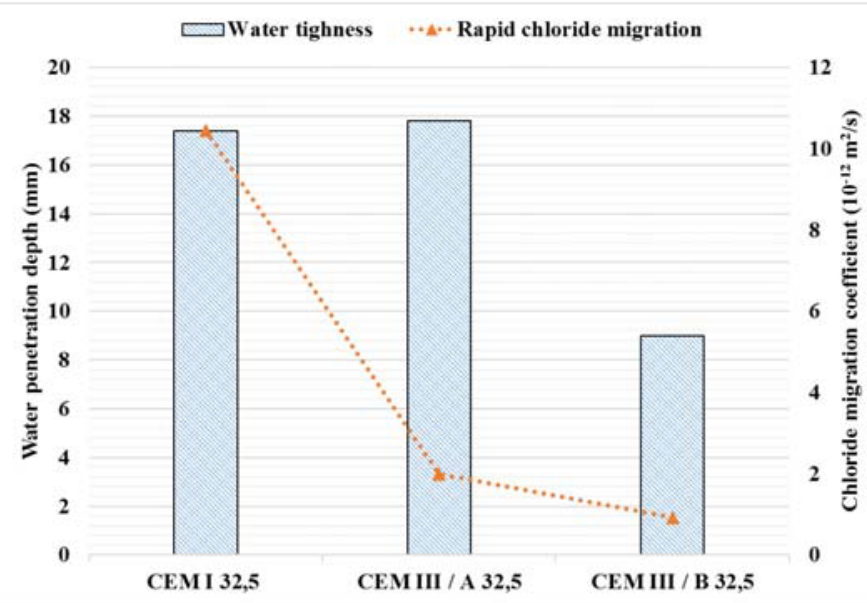

Fig. 5. Water penetration depths and chloride migration coefficients of mixtures.

\section{Environmental performance evaluation}

The reduction of clinker content in the mixture composition could lead to a major reduction of the impact of clinker production on the environment in comparison with mixtures incorporating a higher amount of clinker.

This enhancement is due to clinker replacement by supplementary cementitious materials such as fly ash, slag and limestone powder. However, using such materials with their current economic value and availability in the country may be challenging. Special Slag cement reaching $75 \%$ of slag content, gypsum and other additional materials is produced in Hungary. This composition has an enormous ecological advantage which is clearly distinguished from traditional Portland cement. Thereby, $\mathrm{CO}_{2}$ emission and energy costs are reduced. Fig. 6. shows a comparison between CEM I, CEM III/A, CEM III/B and Slagstar in terms of $\mathrm{CO}_{2}$ emission and energy consumption reduction [16]. The impact of slag cement in reducing the $\mathrm{CO}_{2}$ can be compared with ordinary Portland cement. By slag replacement of the clinker, $\mathrm{CEM} / \mathrm{B} 32.5$ reaching $20 \%$ clinker provided $212 \mathrm{~kg}$ per ton of $\mathrm{CO}_{2}$ emission. Thus critical savings of $\mathrm{CO}_{2}$ emission are achieved.

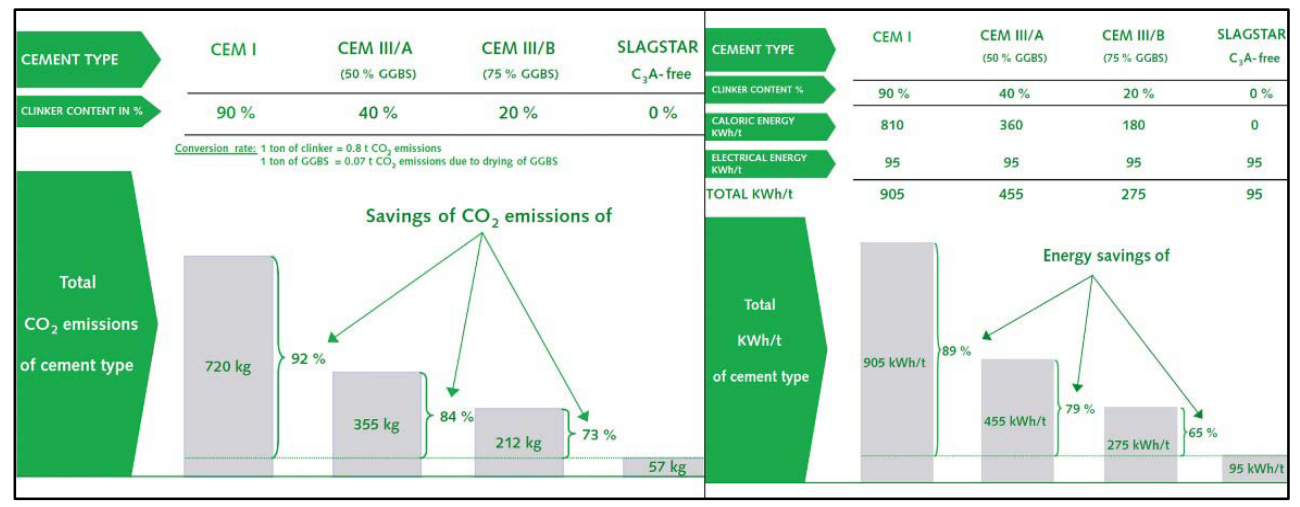

Fig. 6. Comparison of $\mathrm{CO}_{2}$ emissions per ton of cement and the energy consumption in $\mathrm{kWh} / \mathrm{t}$. 


\section{Conclusions}

The purpose of this study was to investigate a low-carbon commercially used cement type (Blast furnace slag). This paper reports the mechanical, thermal and durability properties of concretes containing different cement types. From the experimental observations on the temperature variation, mechanical and durability properties of tested concretes, the following conclusion can be drawn:

1. The introduction of cement with high amount of slag $(65 \%)$ was enabled reaching similar compressive strength values in comparison with cement containing clinker $(93 \%)$ at 28 days of age;

2. Concrete containing a high amount of slag achieved shrinkage values reductions up to $35 \%$ in comparison to the control concrete, with the similar grade and at the same water cement ratio levels;

3. The water tightness results were low in CEM III/B, which indicates an improved and dense concrete microstructure;

4. The chloride impermeability is highly enhanced with the use of slag cement. The chloride permeability was reduced by $90 \%$ with respect to the control mixture;

5. Slag cement are considered environmental friendly providing great reduction in $\mathrm{CO}_{2}$ emission, in comparison with ordinary Portland cement.

\section{References}

1. P. Aitcin, S. Mindess, Sustainability of Concrete (Taylor \& Francis e-Library, 2011)

2. U.S. Department of the Interior, U.S. Geological Survey, Mineral Commodity Summaries 2011 (U.S. Geological Survey, Reston, Virginia, 2011)

3. M. Shariq, J. Prasad, H. Abbas, Cem. Concr. Compos. 68, 35-45 (2016)

4. X. Wang, K. Wang, J. Li, N. Garg, S.P. Shah, J. Sustain. Cem. Mater. 3, 245-255 (2014)

5. S.G. Nehme, Epa. - J. Silic. Based Compos. Mater. 67, 28-33 (2015)

6. BS EN 206:2013, Concrete-specification, performance, production and conformity, Br. Stand. (2013)

7. BS EN12390-3:2009, Testing hardened concrete. Part3: Compressive strength of test specimens, Br. Stand. (2009)

8. BS EN12390-8:2009, Testing hardened concrete. Part 8: Depth of penetration depth of water under pressure, Br. Stand. (2009)

9. NT BUILD 492, nordtest method (1999)

10. S. Miyazawa, T. Yokomuro, E. Sakai, A. Yatagai, N. Nito, K. Koibuchi, Constr. Build. Mater. 61, 90-96 (2014)

11. AS 1379-2007, Specification and supply of concrete (2007)

12. X. Zou, A. Chao, Y. Tian, N. Wu, H. Zhang, T.Y. Yu, X. Wang, Meas. J. Int. Meas. Confed. 45, 1077-1082 (2012)

13. P. Kara, A. Borosnyói, O. Fenyvesi, Epa. - J. Silic. Based Compos. Mater. 66, 18-22 (2014)

14. M.H. Lee, B.S. Khil, H.D. Yun, Indian J. Eng. Mater. Sci. 21, 536-542 (2014)

15. A. Neville, Properties of concrete (fourth ed. Pearson, 1995)

16. R. Novak, W. Schneider, E. Lang, Material Science, 58, 70-78 (2005) 